Evidence for spared attention to faces in 7-month-old infants after prenatal exposure to antiepileptic drugs

\title{
Videman, Mari
}

2016-11

Videman , M , Stjerna , S , Roivainen , R , Nybo , T , Vanhatalo , S , Gaily , E \& Leppanen , J M 2016 , ' Evidence for spared attention to faces in 7-month-old infants after prenatal exposure to antiepileptic drugs ' , Epilepsy \& Behavior, vol. 64 , pp. 62-68 . https://doi.org/10.1016/j.yebeh.2016.09.

http://hdl.handle.net/10138/230921

https://doi.org/10.1016/j.yebeh.2016.09.023

publishedVersion

Downloaded from Helda, University of Helsinki institutional repository.

This is an electronic reprint of the original article.

This reprint may differ from the original in pagination and typographic detail.

Please cite the original version. 


\title{
Evidence for spared attention to faces in 7-month-old infants after prenatal exposure to antiepileptic drugs
}

\author{
Mari Videman ${ }^{\mathrm{a}, *}$, Susanna Stjerna ${ }^{\mathrm{b}}$, Reina Roivainen ${ }^{\mathrm{c}}$, Taina Nybo ${ }^{\mathrm{d}}$, Sampsa Vanhatalo ${ }^{\mathrm{b}}$, \\ Eija Gaily ${ }^{\mathrm{a}}$, Jukka M. Leppänen ${ }^{\mathrm{e}}$ \\ a Children's Hospital, University of Helsinki and Helsinki University Hospital, Finland \\ ${ }^{\mathrm{b}}$ Department of Children's Clinical Neurophysiology, HUS Medical Imaging Center and Children's Hospital, Helsinki University Hospital and University of Helsinki, Finland \\ c Clinical Neurosciences, Neurology, University of Helsinki and Hyvinkää Hospital, Helsinki and Uusimaa Hospital District, Finland \\ d Clinical Neurosciences, Head and Neck Center, Neuropsychology, University of Helsinki and Helsinki University Hospital, Finland \\ e Infant Cognition Laboratory, Center for Child Health Research, School of Medicine, University of Tampere, Finland
}

\section{A R T I C L E I N F O}

\section{Article history:}

Received 25 May 2016

Revised 16 August 2016

Accepted 11 September 2016

Available online 11 October 2016

\section{Keywords:}

Eye-tracking

Epilepsy

Pregnancy

Cognition

AED

Infant

\begin{abstract}
A B S T R A C T
Introduction: Prenatal antiepileptic drug (AED) exposure is associated with an increased risk of cognitive impairment and autism spectrum disorders detected mainly at the age of two to six years. We examined whether the developmental aberrations associated with prenatal AED exposure could be detected already in infancy and whether effects on visual attention can be observed at this early age.

Material and methods: We compared a prospective cohort of infants with in utero exposure to AED $(n=56)$ with infants without drug exposures $(n=62)$. The assessments performed at the age of seven months included standardized neurodevelopmental scores (Griffiths Mental Developmental Scale and Hammersmith Infant Neurological Examination) as well as a novel eye-tracking-based test for visual attention and orienting to faces. Background information included prospective collection of AED exposure data, pregnancy outcome, neuropsychological evaluation of the mothers, and information on maternal epilepsy type.

Results: Carbamazepine, oxcarbazepine, and valproate, but not lamotrigine or levetiracetam, were associated with impaired early language abilities at the age of seven months. The general speed of visuospatial orienting or attentional bias for faces measured by eye-tracker-based tests did not differ between AED-exposed and control infants.

Discussion: Our findings support the idea that prenatal AED exposure may impair verbal abilities, and this effect may be detected already in infancy. In contrast, the early development of attention to faces was spared after in utero AED exposure.
\end{abstract}

() 2016 Elsevier Inc. All rights reserved.

\section{Introduction}

There is a rapidly accumulating literature on the effects of antiepileptic drug (AED) treatment during pregnancy, including both the effects on maternal seizures and epilepsy-related mortality, as well as on the effects on obstetric outcomes [1-5]. Recent data suggest that the effects on structural and functional teratogenesis vary widely between AEDs [6], with most data available on the effects of valproate, carbamazepine, lamotrigine, and phenytoin. In particular, prenatal valproate exposure relates to a relatively higher risk of major malformations, cognitive impairment, and autism spectrum disorders [6-9]. Comparisons between AEDs

Abbreviations: AED, antiepileptic drug; VPA, valproic acid; CBZ, carbamazepine; OXC oxcarbazepine; LEV, levetiracetam; LTG, lamotrigine; TPM, topiramate; VIQ verbal intelligence quotient; PIQ, performance intelligence quotient; HINE, Hammersmith Infant Neurological Examination.

* Corresponding author at: BABA Center, Children's Hospital, Helsinki University Hospital, P.O. Box 280, FIN-00029 HUS, Finland.

E-mail address: mari.videman@hus.fi (M. Videman). suggest that in utero valproate exposure in six-year-old children is associated with an IQ that is 8 to 11 points lower compared with children with in utero exposure to lamotrigine, carbamazepine, or phenytoin [10]. The largest group differences were seen in verbal and memory function.

Despite the growing knowledge of the effects of the AEDs on neurocognition and behavior, the underlying mechanisms and developmental time-course of these consequences are still mainly unknown. One of the proposed mechanisms at cellular level has been altered apoptosis [11-14] contributing to structural changes in the cerebellum [15], hippocampus, and cortex [16]. Functional changes have been suggested to be due to alterations in synaptic maturation, in organization of neuronal networks, and in electric brain activity [13,17-20].

Supporting the hypothesis that AED exposure may alter the development of activity-dependent neural networks, we recently found significant differences in the newborn cortical activity after prenatal exposure to AEDs [20]. These findings suggested that prenatal AED exposure might interfere with temporal occurrence and spatial coordination of the developing brain, possibly leading to functional effects that emerge 
behaviorally in later infancy. Yet very few studies have assessed the early developmental effects [21,22]. Moreover, the changes in AED practices $[23,24]$ have raised the need for assessing the developmental effects of many newer AEDs.

Besides the need for assessing the general effects of AED exposure on early development $[7,9,10,25-27]$, it has become important to assess changes in specific cognitive processes, and in particular, those related to visual functions. Recent developments in eye-tracking-based testing of infant cognition [28-30] have opened new possibilities for automated testing of infants' visual acuity, visuospatial orienting (gaze shifts to a novel visual stimulus), and attention to salient social stimuli, such as faces [31-35]. These processes provide the key "building blocks" of later emerging advanced cognitive, academic, and social skills [36,37]. For instance, speed of visuospatial orienting at 3.5 or 7 months of age will predict cognitive and academic performance at the age of 4 and 11 years [38,39]. Similarly, tests assessing infants' attentional bias for faces at 7 months predict socioemotional development at the age of 14 months [40], and reduced face preference is associated with later autism spectrum disorders [41-46] and atypical development [47]. Compared with traditional observational methods, eye-tracking-based testing of infants allows for completed automatization of the test procedure, as well as accurate, transparent physiological metrics of the sensory and cognitive processes in infants $[33,47,48]$.

The present study was designed to investigate whether prenatal AED exposure is associated with the development of neurological and perceptual abilities at the age of seven months. To this end, we used both standardized neurocognitive testing and novel eye-trackingbased methods that focus on infants' attention orienting and attentional bias for faces [28].

\section{Material and methods}

\subsection{General aspects}

The study was conducted at the Helsinki University Hospital. The ethics committee of the Helsinki University Hospital approved the study. A written informed consent was obtained from all mothers during pregnancy. Background information, exposure data (including daily doses and serum levels for oxcarbazepine (OXC), carbamazepine (CBZ), valproic acid (VPA), lamotrigine (LTG), and levetiracetam (LEV)), pregnancy outcome data, and results of the mothers' neurocognitive evaluation were gathered prospectively and are described in detail in a previous report along with a description of the recruitment process [20].

The initial cohort consisted of 56 newborns with fetal AED exposure and 67 control newborns. Of the AED group, ten infants were exposed to OXC, nine to CBZ, eight to LTG, seven to LEV, five to VPA, one to topiramate monotherapy, and 16 to more than one AED. Mean daily doses in monotherapy group during the first trimester were as follows: CBZ $733 \mathrm{mg}$ (mean serum concentration: $29 \mu \mathrm{mol} / \mathrm{l}$ ), OXC $833 \mathrm{mg}$ ( $30 \mu \mathrm{mol} / \mathrm{l}$ ), LTG $288 \mathrm{mg}(7.1 \mu \mathrm{mol} / \mathrm{l})$, VPA $925 \mathrm{mg}$, (free serum concentration: $28 \mu \mathrm{mol} / \mathrm{l}$ ), and LEV $1571 \mathrm{mg}$ (serum concentrations for LEV were not measured). For more detailed information, see Supplementary material Table S1 and our previous publication [20]. All of the exposed infants and 62 out of 67 control infants of this original cohort participated in clinical neurological and eye-tracker examinations at the age of seven months. Three of the original controls declined participation for personal reasons, one due to moving to another district, and one due to acute illness. The examinations took place at outpatient visits between November 2010 and January 2015. All examiners were blinded to the exposure status of the infants.

\subsection{Clinical neurology}

The Griffiths Mental Developmental Scale [49] was used to evaluate the developmental status of the infant. This scale constitutes of five subscales (locomotor, personal-social, hearing and language, eye and hand coordination, and performance) and total developmental quotient. We converted the raw scores to subquotients and general quotient as described in [49]. To assess the clinical neurological status, we used the Hammersmith Infant Neurological Examination (HINE) [50,51]. It includes three sections: twenty-six neurological items (cranial nerve function, movements, tone, reflexes, and reactions), eight motor milestone items, and three behavior items, altogether 37 items. The first author performed both Griffiths Mental Developmental Scale and HINE examinations.

\subsection{Eye-tracker}

The eye-tracking test was designed to assess infants' attention to nonface patterns and faces by using a face-distractor competition paradigm $[31,40]$. In this paradigm, infants fixate a nonface pattern or a picture of a face in the center of the screen while a lateral distractor stimulus (geometric shape) is presented to the left or to the right. Infants' attention is indexed by the duration of gaze fixation to the pattern/face. The duration is measured until the infant makes a gaze shift to the lateral distractor or a maximum time of $1000 \mathrm{~ms}$ was reached.

During the test, the infants sat in a baby carrier attached on their parent's chest, and a sequence of visual stimuli was presented on a 17-inch TFT monitor integrated in a Tobii T120 eye-tracker device (Tobii Technology AB, Stockholm, Sweden). Before running the actual study protocol, a calibration procedure was performed as explained in detail by Ahtola et al. [31]. The eye-tracking protocol constituted 32 trials. Each trial consisted of two phases, which together lasted for $4000 \mathrm{~ms}$. The trial began by first attracting infant's attention to the center of the screen using simple audiovisual animations, for example, a gradually expanding red circle (diameter from $0.3^{\circ}$ to $4.2^{\circ}$ ) with recurring sound. The trial was programmed to start automatically only after the eye-tracking device had reported $600 \mathrm{~ms}$ of continuous fixation onto the predefined 'fixation area' (diameter: $4.2^{\circ}$ ) around the animation stimulus. During the first $1000 \mathrm{~ms}$, an image of a nonface pattern ('sham') or a face displaying neutral, happy, or fearful expression was shown on the center of the screen. During the remaining $3000 \mathrm{~ms}$, a peripheral "distractor" stimulus was added into the edge of the screen $10.2^{\circ}$ away from the face, equiprobably on the left or right. The order of the central stimulus (a nonface pattern or one of the three faces) and the side of the peripheral stimulus varied randomly with the exception that the same face was presented no more than twice in a row, and the target was no more than three times in a row shown on the same side of the screen. The test has been described in further detail in a previous report $[31,40]$.

To determine the duration of infants' gaze fixations to nonface patterns and faces, we used a library of MATLAB (Mathworks, Natick, MA) functions, designed for automated extraction of the fixation duration parameters from raw eye-tracking data ( $\mathrm{x}-\mathrm{y}$ gaze position coordinates [33]). Briefly, the analysis consisted of the following stages: First, a 15-sample median filter was applied for removing abrupt spikes in the gaze data (attributable to technical artifacts). Second, data segments with a maximum of $200 \mathrm{~ms}$ of missing eye position data were filled by continuing the last recorded $\mathrm{x}$ - and $\mathrm{y}$-coordinates until the tracking came back online. Third, invalid trials were removed from the analyses (i.e., trials with $>200 \mathrm{~ms}$ of missing eye position data, $<70 \%$ of gaze fixation at the first stimulus by the end of the analysis period, anticipatory eye movements with a latency $<150 \mathrm{~ms}$, or computer timing errors). Finally, the duration of gaze fixation at the first stimulus (a nonface pattern or pictures of faces) was calculated for each stimulus condition by using the same criteria as those used in previous studies [33]. The duration index was calculated by measuring the time from the onset of the lateral stimulus to the onset of a gaze shift to the lateral stimulus or a 1000 -ms time limit. Raw time values were converted to proportions so that the index was 0 if the infant made an immediate gaze shift to 
the lateral stimulus (150 ms was used as a cutoff for shortest possible reaction time) and 1 if the infant held gaze at the first stimulus until the end of the analysis period.

The mean duration of gaze fixation (index) reflects infants' general saccadic reaction time or "attention disengagement" time (longer "disengagement times" have been linked to autism $[43,47])$ whereas the relative lengthening of the fixation time in the context of faces (i.e., difference between nonface patterns and faces) reflects infants' attention bias for faces [52]. Reduced attentional bias for faces has been found in children with behavioral problems or autism $[40,53,54]$.

SS performed all eye-tracker examinations. The eye-tracker procedure took maximum $15 \mathrm{~min}$, and infants seemed to enjoy the situation sitting on their parents' lap and watching a screen with changing objects.

\subsection{Statistical analysis}

We compared AED-exposed and control infants with each other. Subgroup analyses of infants with fetal exposure to different AEDs were compared with each other and control infants, infants with fetal AED polytherapy exposure were compared with infants with fetal AED monotherapy exposure, and both of these groups were compared with infants without fetal AED exposure. As some of the data were not normally distributed and group sizes were relatively small and unbalanced, the primary comparisons were executed using nonparametric statistics: Fisher's Exact test, Pearson Chi-Square test, Mann-Whitney U-test, or Kruskal-Wallis test. To evaluate the impact of age of the infant and maternal education and maternal intelligence, we performed additional statistics using one-way between-groups analysis of covariance and two-way between-groups analysis of covariance. The level of significance was set at $\mathrm{p}<0.05$. In cases with multiple comparisons, we applied Bonferroni correction.

\section{Results}

\subsection{Background information}

As described in [20], AED and control groups did not differ significantly concerning the gestational age or gender of the newborn or the age, folic acid supplementation, neurocognitive evaluation, smoking, alcohol consumption, or parity of the mothers. Neuropsychological evaluation [55-57] was performed for 48 mothers of the medication group and of 20 mothers of the control group. There was no significant difference in maternal verbal intelligence quotient (VIQ), performance intelligence quotient (PIQ), or clinically measurable relevant executive functioning skills between the groups: VIQ mean 111 (range: 69-137, SD: \pm 13 ) (AED group) vs. mean 114 (range: 97-134, SD: \pm 10 (controls), $\mathrm{p}=0.54$; PIQ mean 117 (range: 62-138, SD: \pm 12 ) (AED) vs. mean 122 (range: 100-138, SD: \pm 11 ) (controls), $\mathrm{p}=0.07$; and executive problems (no problems/slight problems) 76\%/24\% (AED) vs. $90 \% / 10 \%$ (controls), $\mathrm{p}=0.32$. Furthermore, maternal cognitive abilities did not differ between subgroups except between polytherapy and monotherapy groups and polytherapy and control groups (Table 2). However, infants in the AED group were significantly younger than control infants at the time of both the eye-tracker (7.31 months vs. 7.47 months, $\mathrm{p}=0.009$ ) and the clinical examination (7.46 months vs. 7.25 months, $p=0.001$ ). In addition, the educational level of AED group mothers was significantly lower than of the control group mothers, and the birth weight was lower in the AED group as well as described in our previous report [20].

\subsection{Development and clinical neurology}

The mean general quotient and three out of five mean subquotients of the Griffiths Mental Developmental Scale were significantly lower in the AED-exposed infants compared with the quotients of the unexposed infants (Table 1). As the maternal educational level differed between

\section{Table 1}

Developmental quotients at the age of 7 months, infants exposed to antiepileptic drugs vs unexposed infants.

\begin{tabular}{llll}
\hline Developmental quotients & $\begin{array}{l}\text { AED }(\mathrm{n}=56) \\
\text { mean (range, SD) }\end{array}$ & $\begin{array}{l}\text { Controls }(\mathrm{n}=59) \\
\text { mean }(\text { range, SD) }\end{array}$ & $\mathrm{p}$ \\
\hline Locomotor & $101(73-141,14)$ & $114(81-166,22)$ & $\mathbf{0 . 0 0 2}^{*}$ \\
Personal/social & $96(66-127,13)$ & $105(84-123,9)$ & $<\mathbf{0 . 0 0 1}^{*}$ \\
Hearing and speech & $87(65-119,11)$ & $94(80-110,7)$ & $<\mathbf{0 . 0 0 1}^{*}$ \\
Eye and hand & $94(73-120,11)$ & $95(79-117,9)$ & 0.49 \\
Performance & $95(79-117,9)$ & $93(79-117,6)$ & 0.18 \\
General quotient & $95(77-117,8)$ & $100(85-113,6)$ & $<\mathbf{0 . 0 0 1}^{*}$ \\
\hline
\end{tabular}

Subquotients and general quotients of Griffiths Mental Developmental Scale of 7-monthold infants with (AED) or without (controls) prenatal antiepileptic drug exposure. AED group is compared with control group (Mann-Whitney test).

AED groups include 40 infants exposed prenatally to monotherapy and 16 infants exposed to polytherapy. For the number of different drugs, see Table 2.

* Significant difference after Bonferroni correction.

the exposed and control groups, we conducted two-way betweengroups analysis of variance to measure the impact of maternal educational level on the mean developmental quotients. After adjusting for the mother's educational level, there was still a statistically significant main effect for AED exposure in "personal/social" ( $p<0.001$ ), "hearing and speech" ( $p=0.01)$, "eye and hand" ( $p<0.001)$, and "general quotient" ( $p<0.001)$ categories. However, the effect size was moderate (partial eta squared: $0.16,0.06,0.12$, and 0.15 , respectively). Statistically significant interaction effect between exposure and maternal education was seen only in the category of "eye and hand". Though the maternal intelligence scores did not differ significantly between the AED and control groups, we conducted additional analysis of the Griffiths Mental Developmental Scale quotients including only those infants with information on maternal VIQ and PIQ. This analysis showed a similar trend between exposed and unexposed infants as the main analysis: "locomotor subquotient" ( $p=0.11)$, "personal/social" $(p=0.02)$, "hearing and speech" ( $p=0.003)$, "eye and hand" ( $p=0.53)$, "performance" $(\mathrm{p}=0.04)$, and "general quotient" $(\mathrm{p}=0.06)$. For more detailed data, see Supplementary material (Table S2).

Furthermore, as the ages at the time of the clinical examinations differed between the exposed and control groups, we conducted one-way between-groups analysis of covariance to measure the impact of age on the mean developmental quotients. The independent variable was the exposure status of the infant, and the dependent variables were the mean scores of subquotients and general quotient of the Griffiths Scale. The age of the infant during the examinations was used as the covariate in the analysis. After adjusting for age, there was still a significant difference between AED and control groups in locomotor $(\mathrm{F}(1111)=$ 12.3, $\mathrm{p}=0.001$, partial eta squared: 0.10$)$, in personal-social $(\mathrm{F}(1111)=27.0, \mathrm{p}<0.001$, partial eta squared: 0.20$)$, and in hearing and speech subquotients $(\mathrm{F}(1110)=16.9, \mathrm{p}<0.001$, partial eta squared: 0.13$)$, and in general quotient $(\mathrm{F}(1110)=21.0, \mathrm{p}<0.001$, partial eta squared: 0.16$)$. On the other hand, there was not a significant difference in eye and hand subquotient $(\mathrm{F}(1111)=1.1, \mathrm{p}=0.30$, partial eta squared: 0.01$)$ or in performance subquotient $(\mathrm{F}(1111)=0.22$, $\mathrm{p}=0.64$, partial eta squared 0.002 ).

As an additional post hoc analysis, we excluded from the analysis those infants of the control group that were older than 7.7 months at the time of the clinical examination. The differences between AED and control groups were still seen after excluding these infants though the mean age at the clinical examination did not differ significantly anymore between the groups at the time of the clinical examination (controls: $\mathrm{n}=47$, mean age: 7.34 months, range: 6.83-7.69, SD: \pm 0.24 and AED: $\mathrm{n}=55$, mean: 7.25 months, range: 6.50-8.27, SD: \pm 0.37 ; $\mathrm{p}=0.09$ ) or at the time of eye-tracker (7.39 months, 6.80-7.80, 0.25 vs. 7.31, $6.50-8.23,0.34$, respectively; $\mathrm{p}=0.12$ ). The results of this post hoc analysis are shown as Supplementary material (Table S3).

In subgroup analyses, infants with CBZ, OXC, and VPA monotherapy exposure had significantly lower mean developmental subquotients in 
the category of hearing and speech than control infants. In addition, CBZ-exposed infants' mean personal-social subquotient and VPAexposed infants' mean general quotient were significantly lower than the quotients of the control infants. Results of the subgroup analyses are shown in Table 2. In the monotherapy group, the results were consistent with the results of the whole AED groups, but surprisingly, statistically significant differences were not observed when comparing the polytherapy group with controls (Table 2).

The mean overall score of 26 neurological items of HINE was lower in the AED group compared with that in the control group (mean score: 50 , range: $46-52$, SD: \pm 2 vs. $51,48-52, \pm 1.0 ; p<0.001)$. On the other hand, in the individual scores, there was only one statistically significant difference between the exposed and unexposed infants in the neurological evaluation at the age of seven months. Fewer of the AED-exposed infants showed a prompt reaction to lateral tilting in section "Reflexes and reactions" than control infants (45\% vs. $55 \%$, $\mathrm{p}=0.004)$. In HINE analyses, the age of the infant had a major role, and therefore, the 7.7-month age limit for control infants as described above was applied.

\subsection{Eye-tracking}

The number of valid trials did not differ significantly between AED and control groups as the percentage of infants having the maximum (eight) trials was as follows (AED vs. controls): sham $69 \%$ vs. $71 \%(\mathrm{p}=0.13)$, neutral $69 \%$ vs. $71 \%(\mathrm{p}=0.85)$, happy $73 \%$ vs. $68 \%$ $(\mathrm{p}=0.17)$, and fear $73 \%$ vs. $66 \%(\mathrm{p}=0.54)$. One infant from the AED group was excluded from the analyses because of an insufficient number of accepted eye-tracker trials ( $<3$ per stimulus).

There were no significant differences in eye-tracker indexes between AED-exposed and control infants (Fig. 1). As the ages at the time of the eye-tracker examination differed between the exposed and control groups, we conducted one-way between-groups analysis of covariance to measure the impact of age on the parameters of eyetracker examination. The independent variable was the exposure status of the infant, and the dependent variable was the index of the eyetracker examination. Neutral, happy, fear, and sham indexes were calculated separately. The ages of the infants during the examinations were used as the covariate in the analysis. After adjusting for age, there was no significant difference between AED and control groups: $F(1113)=1.61, p=0.21$ for index of sham; $F(1114)=0.68, p=0.42$ for index of neutral; $F(1114)=0.56, p=0.46$ for index of happy; and $F(1114)=3.43, p=0.07$ for index of fear. There was no statistically significant association relationship between the age of the infant and of the eye-tracker indexes, as indicated by a partial eta squared value of 0.01 for index of sham, of 0.01 for index of neutral, of 0.01 for index of happy, and of 0.03 for index of fear. As an additional post hoc analysis, we matched the two groups for age by excluding those infants of the control group that were older than 7.7 months at the time of the clinical examination. This analysis showed that the results reported above did not change when the age difference between the groups was eliminated. Results are demonstrated in Supplementary material Table S4.

In subgroup analyses, eye-tracker indexes did not differ between infants with monotherapy exposure and controls, polytherapy exposure and controls, or monotherapy and polytherapy exposure. The comparisons of each AED monotherapy group against another or with controls did not reveal any significant differences between the groups (Supplementary material Tables S4 and S5). Eye-tracker indexes were overall higher in infants exposed to LEV implying that the mean latency of the eye gaze shifts (and, consequently, visual orienting responses) was slower, but taking into account Bonferroni corrections, the result was not significant. The mean ages of LEV and control groups were comparable at the time of eye-tracker examination.

\section{Discussion}

To our knowledge, this is the first study to evaluate neurocognitive effects of prenatal AED exposure at the age of seven months and, in particular, to measure AED effects on an infant's visual orienting and

Table 2

Developmental quotients at the age of 7 months, infants exposed prenatally to antiepileptic drugs: subgroup analyses.

\begin{tabular}{|c|c|c|c|c|c|c|c|c|}
\hline $\begin{array}{l}\text { Developmental quotients } \\
\text { mean (range, SD, p) }\end{array}$ & Controls $(n=59)$ & $\mathrm{CBZ}(\mathrm{n}=9)$ & $\mathrm{OXC}(\mathrm{n}=10)$ & $\operatorname{VPA}(n=5)$ & LTG $(n=8)$ & $\operatorname{LEV}(\mathrm{n}=7)$ & $\begin{array}{l}\text { Monotherapy } \\
(\mathrm{n}=40)\end{array}$ & $\begin{array}{l}\text { Polytherapy } \\
(\mathrm{n}=16)\end{array}$ \\
\hline Locomotor & $114(81-166,22)$ & $\begin{array}{l}104(88-115,8 \\
p=0.32)\end{array}$ & $\begin{array}{l}104(81-130,15 \\
p=0.21)\end{array}$ & $\begin{array}{l}91(86-102,8 \\
p=0.01)\end{array}$ & $\begin{array}{l}97(86-106,7 \\
p=0.03)\end{array}$ & $\begin{array}{l}102(93-112,6, \\
p=0.27)\end{array}$ & $\begin{array}{l}101(81-130,10 \\
\left.\mathbf{p}=\mathbf{0 . 0 0 2}^{*}\right)\end{array}$ & $\begin{array}{l}102(73-141,20 \\
p=0.11)\end{array}$ \\
\hline Personal/social & $105(84-123,9)$ & $\begin{array}{l}95(85-108,8 \\
\left.\mathbf{p}=\mathbf{0 . 0 0 3}^{*}\right)\end{array}$ & $\begin{array}{l}97(78-117,13 \\
p=0.06)\end{array}$ & $\begin{array}{l}88(66-111,19 \\
p=0.07)\end{array}$ & $\begin{array}{l}96(83-108,9 \\
p=0.02)\end{array}$ & $\begin{array}{l}98(85-112,12, \\
p=0.25)\end{array}$ & $\begin{array}{l}96(66-120,12, \\
\left.\mathbf{p}<\mathbf{0 . 0 0 1}^{*}\right)\end{array}$ & $\begin{array}{l}95(74-127,14 \\
p=0.03)\end{array}$ \\
\hline Hearing and speech & $94(80-110,7)$ & $\begin{array}{l}83(66-92,9 \\
\left.\mathbf{p}=\mathbf{0 . 0 0 1}^{*}\right)\end{array}$ & $\begin{array}{l}85(73-96,8 \\
\mathbf{p}=\mathbf{0 . 0 0 2})\end{array}$ & $\begin{array}{l}79(65-89,10 \\
\left.\mathbf{p}=\mathbf{0 . 0 0 5}^{*}\right)\end{array}$ & $\begin{array}{l}90(68-109,15 \\
p=0.35)\end{array}$ & $\begin{array}{l}90(77-102,11, \\
\mathrm{p}=0.44)\end{array}$ & $\begin{array}{l}86(65-109,11, \\
\left.\mathbf{p}<\mathbf{0 . 0 0 1}^{*}\right)\end{array}$ & $\begin{array}{l}91(73-11912 \\
\mathrm{p}=0.21)\end{array}$ \\
\hline Eye and hand & $95(79-117,9)$ & $\begin{array}{l}99(78-117,11, \\
p=0.14)\end{array}$ & $\begin{array}{l}88(74-104,8 \\
p=0.03)\end{array}$ & $\begin{array}{l}84(73-93,9 \\
p=0.04)\end{array}$ & $\begin{array}{l}95(82-104,8 \\
p=0.99)\end{array}$ & $\begin{array}{l}94(89-112,8 \\
p=0.84)\end{array}$ & $\begin{array}{l}94(73-117,10 \\
p=0.59)\end{array}$ & $\begin{array}{l}95(81-120,12 \\
\mathrm{p}=0.54)\end{array}$ \\
\hline Performance & $93(79-117,6)$ & $\begin{array}{l}94(82-102,8 \\
p=0.46)\end{array}$ & $\begin{array}{l}94(81-106,9 \\
p=0.85)\end{array}$ & $\begin{array}{l}96(79-109,13 \\
p=0.28)\end{array}$ & $\begin{array}{l}96(90-108,5 \\
p=0.33)\end{array}$ & $\begin{array}{l}97(85-115,11, \\
\mathrm{p}=0.69)\end{array}$ & $\begin{array}{l}95(79-115,8 \\
p=0.17)\end{array}$ & $\begin{array}{l}95(81-117,10 \\
p=0.56)\end{array}$ \\
\hline General quotient & $100(85-113,6)$ & $\begin{array}{l}95(87-105,5 \\
\mathrm{p}=0.02)\end{array}$ & $\begin{array}{l}94(79-105,7 \\
\mathrm{p}=0.01)\end{array}$ & $\begin{array}{l}88(77-96,9 \\
\left.\mathbf{p}=\mathbf{0 . 0 0 8}^{*}\right)\end{array}$ & $\begin{array}{l}95(89-99,5 \\
\mathrm{p}=0.03)\end{array}$ & $\begin{array}{l}96(87-105,6 \\
p=0.15)\end{array}$ & $\begin{array}{l}94(77-106,6 \\
\left.\mathbf{p}<\mathbf{0 . 0 0 1}^{*}\right)\end{array}$ & $\begin{array}{l}97(81-117,10 \\
p=0.19)\end{array}$ \\
\hline
\end{tabular}

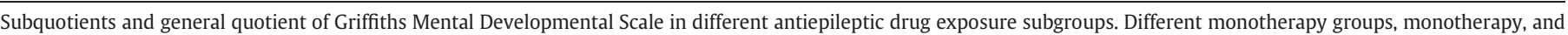
polytherapy groups are compared with controls (Mann-Whitney test).

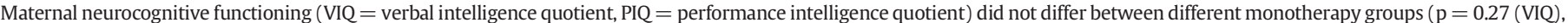

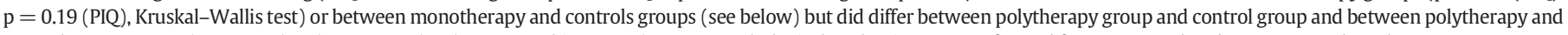
monotherapy groups ( $\mathrm{p}=0.01$ (VIQ), $\mathrm{p}=0.02$ (PIQ), Mann-Whitney test). Neuropsychological evaluation was performed for 48 exposed and 20 unexposed mothers.

CBZ (VIQ mean: 116, range: 94-131, SD: $\pm 10, \mathrm{p}=0.49$; PIQ 120, 102-129, $\pm 9, \mathrm{p}=0.082$ ).

OXC (VIQ mean: 108, range: 75-137, SD: $\pm 17, \mathrm{p}=0.27$; PIQ 116, 94-128, $\pm 11, \mathrm{p}=0.22$ ).

VPA (VIQ mean: 109, range: $87-122$, SD: $\pm 14, \mathrm{p}=0.59$; PIQ 113, 100-119, $\pm 9, \mathrm{p}=0.07$ ).

LTG (VIQ mean: 113, range: $100-125$, SD: $\pm 10, \mathrm{p}=0.91$; PIQ 122, 113-138, $\pm 8, \mathrm{p}=0.72$ ).

LEV (VIQ mean: 118, range: 109-131, SD: $\pm 9, \mathrm{p}=0.42$; PIQ 121, 112-132, $\pm 8, \mathrm{p}=0.52$ ).

Monotherapy (VIQ mean: 114, range: 75-137, SD: $\pm 13, \mathrm{p}=0.81 ;$ PIQ 119, 94-138, $\pm 9, \mathrm{p}=0.27$ ).

Polytherapy (VIQ mean: 104, range: 69-119, SD: $\pm 13, \mathrm{p}=0.02$; PIQ 110, 62-121, $\pm 15, \mathrm{p}=0.006$ ).

Controls (VIQ mean: 114, range: 97-134, SD: \pm 10 ; PIQ 122, 100-138, \pm 11 ).

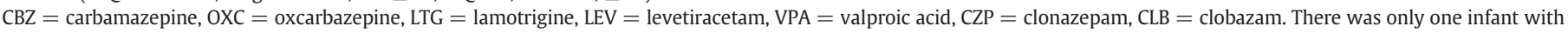
topiramate monotherapy, and this child was included as part of monotherapy group.

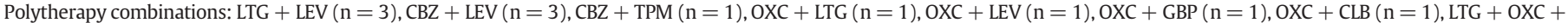
CZP $(n=1)$, LTG + LEV + CZP $(n=3)$, LTG + TPM + CLB $(n=1)$.

* Significant difference after Bonferroni correction. 

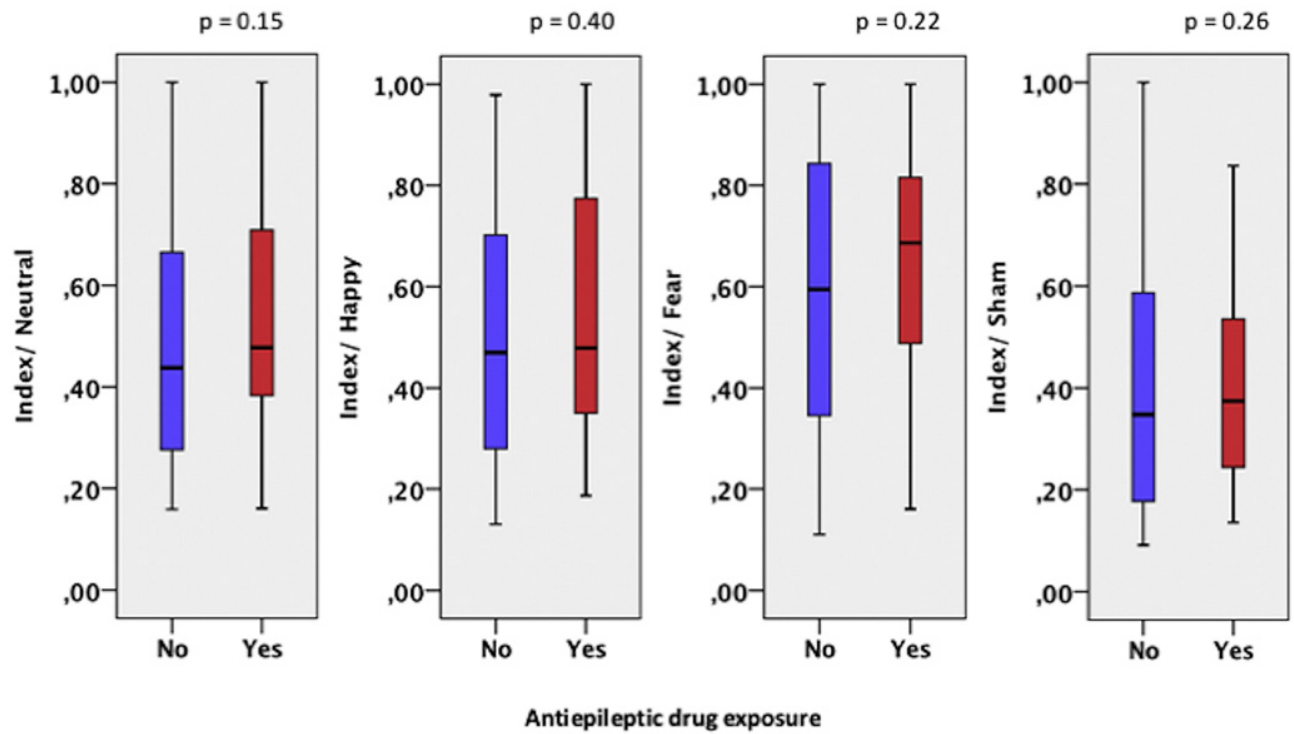

Antiepileptic drug exposure

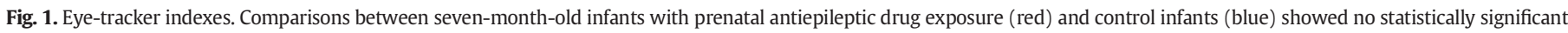

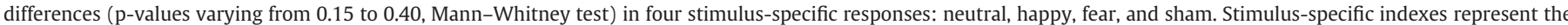

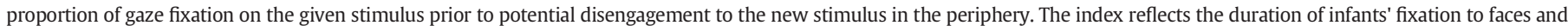

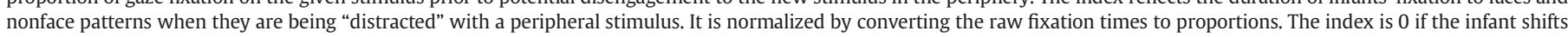

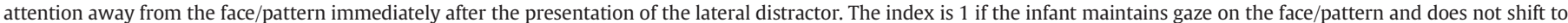
the lateral distractor by the maximum time limit of $1000 \mathrm{~ms}$. Boxes equal medians of eye-tracker indexes, and whisker lines interquartile ranges.

attention. In line with earlier studies on older children [5,10,14,26,27,58], we found prenatal AED exposure to compromise the development of early language and social skills, as well as overall neurodevelopment at the age of seven months. However, our eye-tracker-based assessment suggests that the general speed of visuospatial orienting (or "disengagement") as well as attentional bias for faces is spared at the age of seven months in infants with prenatal AED exposure.

\subsection{Development and neurological status neurology}

Our study implies that prenatal exposure to VPA, CBZ, or OXC (a structural analogue of CBZ) monotherapy may have effects on the development of the exposed children (Table 2), and they can be observed already at the age of seven months. In concordance with previous studies on older children $[10,14,26,58]$, we found the most prominent effects in the overall development (general quotient), as well as in verbal (subquotient of hearing and speech) and social (subquotient of personal-social) developments. These observations suggest that the precursors of verbal impairments detected at the age of 4.5 to 6 years $[10,26,58]$ may, indeed, be observed during the first year of life. Deviations of early development at the age of eight months have been discovered before in infants of women with epilepsy taking phenobarbital or phenytoin during pregnancy, but the developmental scores showed only random variation according to AED exposure, and it remained unclear whether the developmental changes were due to AED or epilepsy per se [21]. The results of Griffiths Mental Developmental Scale (Table 2) suggested that LTG and LEV may differ from CBZ, OXC, and VPA in regard to early language abilities (subquotient of hearing and speech). In a recent study from Baker et al. [26], both VPA and CBZ were associated with reduced verbal abilities at the age of six years as well.

The long-term clinical relevance of the difference in global scores of HINE of the AED-exposed children remains to be shown. The HINE was primarily developed to assess the infant neurological status rather than to predict future developmental outcomes [50]. The global as well as some individual HINE scores are predictive of cerebral palsy $[59,60]$; however, other outcomes correlate less with HINE. The very low incidence of $\mathrm{CP}$ ( 1 per 1000 live births) in populations like ours
[61] makes it unlikely that our present findings are predictive of CP-related morbidities.

\subsection{Visual orienting of attention}

Our results showed no difference in fixation durations for nonface patterns and faces between AED-exposed children and controls. Given that the test task performance was technically successful and very comparative with many previous studies [40,43], the lack of differences cannot be attributed to methodological issues in test administration. Furthermore, earlier work has shown that the eye-tracking-based method is sensitive enough to measure clinically subtle effects such as single nucleotide gene polymorphisms or preterm birth; both were shown to affect eye-tracking-based measures [62-64]. Thus, we would conclude that the present observations are valid and may tentatively speak for relative sparing of attention to faces in AED-exposed infants. Future studies may examine whether this result generalizes to other eye-tracking-based tests of infant cognition, given results suggesting that nonsocial and social attention may be based on partially independent mechanisms in infants [30] and the current results showing specific problems in language-related tasks in AED-exposed infants.

A post hoc comparison with respect to different AED exposures suggested that LEV-exposed infants tend to have a slower gaze shift compared with control infants (Supplemental material Table S3). The underlying neurobiological mechanisms of LEV-related effects are not clear; however, LEV is known to target diverse molecular mechanisms that are distinct from the more traditional AEDs [65,66].

\subsection{Strengths and limitations}

Our study process included a prospective collection of exposure and background data for all excluded pregnancies allowing for the estimation of recruitment bias that cannot be achieved in registry studies [20]. The drop-off rate during postnatal follow-up was exceptionally low. Neuropsychological evaluation of the mothers was included, though for differences in recruitment process (see [20]), only $30 \%$ of the control mothers were examined. To assess the neurocognitive development of the infants, we used well-established structured 
methods [49-51] and the quantitative eye-tracker approach, which has been described and tested in previous studies [31].

The range of medications in our study (CBZ, OXC, LEV, LTG, VPA) corresponds to current medication trends $[23,24]$. Because of a small number of children, our study did not have enough power to reliably assess possible differences between different monotherapy groups or between specific monotherapy or other subgroups and controls, though some developmental differences were indicated. The mean age of the infants during the examination and the educational level of the mothers were higher in the control group, but the results remained similar when these confounding factors were taken into account.

\section{Conclusions}

According to our study, verbal impairments after prenatal AED exposure can be detected already in infancy. In contrast, social visuospatial attention or face perception abilities may be less vulnerable to functional teratogenic effects of the AEDs.

Eye-tracking-based testing can be easily administered in clinical settings and may prove to be useful techniques in the early assessment of infants with suspected problems in visuospatial orienting and/or face perception. Our follow-up study at the age of two years is awaited to disclose potential effects of these infant findings on the longer-term developmental trajectories.

\section{Acknowledgments and funding}

The work was supported by Foundation for Pediatric Research, Arvo and Leo Ylppö Foundation, Lastenlinna Foundation, Juselius Foundation, Märta Donner Foundation, Päivikki and Sakari Sohlberg Foundation, Academy of Finland (grant 288220, 276523), and Finnish Cultural Foundation.

\section{Disclosure}

None of the authors has any conflict of interest to disclose.

\section{Appendix A. Supplementary data}

Supplementary data to this article can be found online at http://dx. doi.org/10.1016/j.yebeh.2016.09.023.

\section{References}

[1] Chen YH, Chiou HY, Lin HC, Lin HL. Affect of seizures during gestation on pregnancy outcomes in women with epilepsy. Arch Neurol 2009;66:979-84.

[2] Edey S, Moran N, Nashef L. SUDEP and epilepsy-related mortality in pregnancy. Epilepsia 2014;55:e72-4.

[3] Sveberg L, Svalheim S, Tauboll E. The impact of seizures on pregnancy and delivery. Seizure 2015;28:35-8.

[4] Borthen I. Obstetrical complications in women with epilepsy. Seizure 2015;28:32-4.

[5] Bromley R. The treatment of epilepsy in pregnancy: the neurodevelopmental risks associated with exposure to antiepileptic drugs. Reprod Toxicol 2016;64:203-10.

[6] Gerard EE, Meador KJ. Managing epilepsy in women. Continuum (Minneap Minn) 2016;22:204-26.

[7] Christensen J, Gronborg TK, Sorensen MJ, et al. Prenatal valproate exposure and risk of autism spectrum disorders and childhood autism. JAMA 2013;309:1696-703.

[8] Tomson T, Xue H, Battino D. Major congenital malformations in children of women with epilepsy. Seizure 2015;28:46-50.

[9] Meador KJ, Loring DW. Developmental effects of antiepileptic drugs and the need for improved regulations. Neurology 2016;86:297-306.

[10] Meador KJ, Baker GA, Browning N, et al. Fetal antiepileptic drug exposure and cognitive outcomes at age 6 years (NEAD study): a prospective observational study. Lancet Neurol 2013;12:244-52.

[11] Bittigau P, Sifringer M, Genz K, et al. Antiepileptic drugs and apoptotic neurodegeneration in the developing brain. Proc Natl Acad Sci U S A 2002;99:15089-94

[12] Bittigau P, Sifringer M, Ikonomidou C. Antiepileptic drugs and apoptosis in the developing brain. Ann N Y Acad Sci 2003;993:103-14 [discussion 123-4].

[13] Ikonomidou C. Prenatal effects of antiepileptic drugs. Epilepsy Curr 2010;10:42-6.

[14] Inoyama K, Meador KJ. Cognitive outcomes of prenatal antiepileptic drug exposure. Epilepsy Res 2015;114:89-97.
[15] Ogura H, Yasuda M, Nakamura S, Yamashita H, Mikoshiba K, Ohmori H. Neurotoxic damage of granule cells in the dentate gyrus and the cerebellum and cognitive deficit following neonatal administration of phenytoin in mice. J Neuropathol Exp Neurol 2002;61:956-67.

[16] Aberg E, Holst S, Neagu A, Ogren SO, Lavebratt C. Prenatal exposure to carbamazepine reduces hippocampal and cortical neuronal cell population in new-born and young mice without detectable effects on learning and memory. PLoS One 2013;8, e80497.

[17] Forcelli PA, Janssen MJ, Vicini S, Gale K. Neonatal exposure to antiepileptic drugs disrupts striatal synaptic development. Ann Neurol 2012;72:363-72.

[18] Verrotti A, Scaparrotta A, Cofini M, Chiarelli F, Tiboni GM. Developmental neurotoxicity and anticonvulsant drugs: a possible link. Reprod Toxicol 2014;48:72-80.

[19] Cusmano DM, Mong JA. In utero exposure to valproic acid changes sleep in juvenile rats: a model for sleep disturbances in autism. Sleep 2014;37:1489-99.

[20] Videman M, Tokariev A, Stjerna S, Roivainen R, Gaily E, Vanhatalo S. Effects of prenatal antiepileptic drug exposure on newborn brain activity. Epilepsia 2016;57:252-62.

[21] Shapiro S, Hartz SC, Siskind V, et al. Anticonvulsants and parental epilepsy in the development of birth defects. Lancet 1976;1:272-5.

[22] Wide K, Winbladh B, Tomson T, Sars-Zimmer K, Berggren E. Psychomotor development and minor anomalies in children exposed to antiepileptic drugs in utero: a prospective population-based study. Dev Med Child Neurol 2000;42:87-92.

[23] Ackers R, Besag FM, Wade A, Murray ML, Wong IC. Changing trends in antiepileptic drug prescribing in girls of child-bearing potential. Arch Dis Child 2009;94:443-7.

[24] Vajda FJ, Hollingworth S, Graham J, et al. Changing patterns of antiepileptic drug use in pregnant Australian women. Acta Neurol Scand 2010;121:89-93.

[25] Bromley R, Weston J, Adab N, et al. Treatment for epilepsy in pregnancy: neurodevelopmental outcomes in the child. Cochrane Database Syst Rev 2014;10, CD010236.

[26] Baker GA, Bromley RL, Briggs M, et al. IQ at 6 years after in utero exposure to antiepileptic drugs: a controlled cohort study. Neurology 2015;84:382-90.

[27] Velez-Ruiz NJ, Meador KJ. Neurodevelopmental effects of fetal antiepileptic drug exposure. Drug Saf 2015;38:271-8.

[28] Gredeback G, Johnson S, von Hofsten C. Eye tracking in infancy research. Dev Neuropsychol 2010;35:1-19.

[29] Oakes L. Advances in eye tracking in infancy research. Infancy 2012;17:1-8.

[30] Gillespie-Smith K, Boardman JP, Murray IC, Norman JE, O'Hare A, Fletcher-Watson S. Multiple measures of fixation on social content in infancy: evidence for a single social cognitive construct? Infancy 2016;21:241-57.

[31] Ahtola E, Stjerna S, Yrttiaho S, Nelson CA, Leppänen JM, Vanhatalo S. Dynamic eye tracking based metrics for infant gaze patterns in the face-distractor competition paradigm. PLoS One 2014;9, e97299.

[32] Jones PR, Kalwarowsky S, Atkinson J, Braddick OJ, Nardini M. Automated measurement of resolution acuity in infants using remote eye-tracking. Invest Ophthalmol Vis Sci 2014;55:8102-10.

[33] Leppänen JM, Forssman L, Kaatiala J, Yrttiaho S, Wass S. Widely applicable MATLAB routines for automated analysis of saccadic reaction times. Behav Res Methods 2015;47:538-48.

[34] Kulke L, Atkinson J, Braddick O. Automatic detection of attention shifts in infancy: eye tracking in the fixation shift paradigm. PLoS One 2015;10, e0142505.

[35] Wass S, Forssman L, Leppänen J. Robustness and precision. How data quality may influence key dependent variables in infant eyetracker analyses. Infancy 2014;19: 427-60.

[36] Rose SA, Feldman JF, Jankowski JJ. The building blocks of cognition. J Pediatr 2003; 143:S54-61.

[37] Stjerna S, Sairanen V, Gröhn R, et al. Visual fixation in human newborns correlates with extensive white matter networks and predicts long-term neurocognitive development. J Neurosci 2015;35:4824-9.

[38] Dougherty TM, Haith MM. Infant expectations and reaction time as predictors of childhood speed of processing and IQ. Dev Psychol 1997;33:146-55.

[39] Rose SA, Feldman JF, Jankowski JJ. Implications of infant cognition for executive functions at age 11. Psychol Sci 2012;23:1345-55.

[40] Peltola MJ, Forssman L, Puura K, van IJzendoorn MH, Leppänen JM. Attention to faces expressing negative emotion at 7 months predicts attachment security at 14 months. Child Dev 2015;86:1321-32.

[41] Senju A, Johnson MH. Atypical eye contact in autism: models, mechanisms and development. Neurosci Biobehav Rev 2009;33:1204-14

[42] Chawarska K, Volkmar F, Klin A. Limited attentional bias for faces in toddlers with autism spectrum disorders. Arch Gen Psychiatry 2010;67:178-85.

[43] Elison JT, Paterson SJ, Wolff JJ, et al. White matter microstructure and atypical visual orienting in 7-month-olds at risk for autism. Am J Psychiatry 2013;170:899-908.

[44] Klin A, Shultz S, Jones W. Social visual engagement in infants and toddlers with autism: early developmental transitions and a model of pathogenesis. Neurosci Biobehav Rev 2015;50:189-203.

[45] Bolte S, Bartl-Pokorny KD, Jonsson U, et al. How can clinicians detect and treat autism early? Methodological trends of technology use in research. Acta Paediatr 2016;105:137-44

[46] Pierce K, Marinero S, Hazin R, McKenna B, Barnes CC, Malige A. Eye tracking reveals abnormal visual preference for geometric images as an early biomarker of an autism spectrum disorder subtype associated with increased symptom severity. Biol Psychiatry 2016;79:657-66.

[47] Papageorgiou KA, Smith TJ, Wu R, Johnson MH, Kirkham NZ, Ronald A. Individual differences in infant fixation duration relate to attention and behavioral control in childhood. Psychol Sci 2014;25:1371-9.

[48] Crawford H, Moss J, Oliver C, Elliott N, Anderson GM, McCleery JP. Visual preference for social stimuli in individuals with autism or neurodevelopmental disorders: an eye-tracking study. Mol Autism 2016;7 [24,016-0084-X., eCollection 2016]. 
[49] Brandt I, Sticker E. GES griffiths entwicklungsskalen: Zur beurteilung der entwicklung in den ersten beiden lebensjahren. 2nd ed. Deutchland: Hogrefe Verlag; 2001.

[50] Haataja L, Mercuri E, Regev R, et al. Optimality score for the neurologic examination of the infant at 12 and 18 months of age. J Pediatr 1999;135:153-61.

[51] Haataja L, Cowan F, Mercuri E, Bassi L, Guzzetta A, Dubowitz L. Application of a scorable neurologic examination in healthy term infants aged 3 to 8 months. J Pediatr 2003;143:546.

[52] Leppänen J. Using eye tracking to understand infants' attentional bias for faces. Child Dev Perspect 2016;10(3):161-5.

[53] Chawarska K, Shic F, Macari S, et al. 18-Month predictors of later outcomes in younger siblings of children with autism spectrum disorder: a baby siblings research consortium study. J Am Acad Child Adolesc Psychiatry 2014;53 [1317,1327.e1].

[54] Bedford R, Pickles A, Gliga T, et al. Additive effects of social and non-social attention during infancy relate to later autism spectrum disorder. Dev Sci 2014;17:612-20.

[55] Stroop J. Studies of interference in serial verbal reactions. J Exp Psychol 1935;18: 643-62.

[56] Rey A. Psychological examination of traumatic encephalopathy. Arch Psychol Translated by Corwin J \& Bylsma FW. Clin Neuropsychol 1993;1941(7):4-9.

[57] Wechsler D. Wechsler adult intelligence scale-3rd edition (WAIS-3®). San Antonio, TX: The Psychological Corporation; 1997[Finnish edition: Psykologien Kustannus Oy, Helsinki, 2005].

[58] Gaily E, Kantola-Sorsa E, Hiilesmaa V, et al. Normal intelligence in children with prenatal exposure to carbamazepine. Neurology 2004;62:28-32.
[59] Pizzardi A, Romeo DM, Cioni M, Romeo MG, Guzzetta A. Infant neurological examination from 3 to 12 months: predictive value of the single items. Neuropediatrics 2008;39:344-6.

[60] Heineman KR, Hadders-Algra M. Evaluation of neuromotor function in infancy-a systematic review of available methods. J Dev Behav Pediatr 2008;29:315-23.

[61] Hirvonen M, Ojala R, Korhonen P, et al. Cerebral palsy among children born moderately and late preterm. Pediatrics 2014;134:e1584-93.

[62] Leppänen JM, Peltola MJ, Puura K, Mäntymaa M, Mononen N, Lehtimäki T. Serotonin and early cognitive development: variation in the tryptophan hydroxylase 2 gene is associated with visual attention in 7-month-old infants. J Child Psychol Psychiatry 2011;52:1144-52.

[63] Forssman L, Peltola MJ, Yrttiaho S, et al. Regulatory variant of the TPH2 gene and early life stress are associated with heightened attention to social signals of fear in infants. J Child Psychol Psychiatry 2014;55:793-801.

64] Telford EJ, Fletcher-Watson S, Gillespie-Smith K, et al. Preterm birth is associated with atypical social orienting in infancy detected using eye tracking. J Child Psychol Psychiatry 2016.

[65] Abou-Khalil BW. Antiepileptic drugs. Continuum (Minneap Minn) 2016;22:132-56.

[66] Wright C, Downing J, Mungall D, et al. Clinical pharmacology and pharmacokinetics of levetiracetam. Front Neurol 2013;4:192. 